\title{
El proceso de literaturización de los primeros textos de las cárceles femeninas del periodo franquistas (1970-1980).
}

\author{
The process of literaturization of the first texts of the Franco \\ women's prisons (1970-1980).
}

Esta obra está bajo una Licencia Creative Commons Atribución 4.0 Internacional. DOI: $\underline{10.32870 / \text { sincronia.axxii.n74.17b18 }}$

\author{
Berta Carrasco de Miguel \\ Hope College, Michigan \\ (ESTADOS UNIDOS) \\ carrasco@hope.edu
}

Recibido: $16 / 10 / 2017$

Revisado: $23 / 01 / 2018$

Aprobado: $17 / 04 / 2018$

\section{RESUMEN}

Los textos que versan sobre las cárceles femeninas del periodo franquista han recibido poca atención por parte de la crítica literaria. Sin embargo, estas obras resultan imprescindibles a la hora de estudiar el panorama literario e histórico del siglo XX. Entendiendo que la historia y la literatura son dos disciplinas complementarias vamos a analizar En el infierno. Ser mujer en las cárceles de España (1977), escrita por Lidia Falcón, Desde la noche y la niebla (1978), de Juana Doña, y Las cárceles de Soledad Real (1982) de Consuelo García, para así presentar el proceso de literaturización que sufren estos textos.

Palabras clave: Cárceles de mujeres. Guerra Civil española. Dictadura. Literaturización. Textos memorialísticos. Testimonio. Manifiesto.

\section{ABSTRACT}

The written works that deal with women in female Francoist prisons have barely received any attention by literary criticism. However, these works are essential to understand the literary and historical state of the $20^{\text {th }}$ century. Understanding that History and Literature are disciplines that complement each other, we are going to analyize En el infierno. Ser mujer en las cárceles de España (1977), written by Lidia Falcón, Desde la noche y la niebla (1978), Juana Doña's work, y Las cárceles 
de Soledad Real (1982), written by Consuelo García in order to present how these factual texts become literature artifacts.

Keywords: Female prisons. Spanish Civil war. Dictatorship. Process of writing. Memorialistic texts. Testimonio. Manifesto.

Cualquier país que experimenta una guerra civil ve, al finalizar la misma, cómo la población que se ha salvado pasa indefectiblemente a formar parte de uno de estos dos grupos: el de los vencedores o el de los vencidos. Los integrantes del primer grupo gozarán del beneplácito que les otorga saberse prosélitos del grupo que pasa a ejerce el poder. Los ciudadanos del segundo tendrán que elegir entre tres opciones: el exilio, el ostracismo político y social o el ejercicio de la lucha contra el nuevo sistema político con todos los riesgos que esto conlleva. El caso de la Guerra Civil española (1936-1939) y la consiguiente dictadura (1939-1975) son un ejemplo claro de esta realidad. Al finalizar la guerra civil, el dictador Francisco Franco impuso un sistema de represión a través del cual toda persona clasificada como vencida que no optó por la aquiescencia a su régimen debía de ser encarcelada, juzgada y en muchos casos aniquilada. Las cárceles franquistas se llenaron de personas que día a día y experiencia a experiencia comenzaron a entretejer los episodios de la historia no oficial: la que el régimen franquista nunca escribió y la que el periodo de Transición entre la dictadura y la democracia procuró silenciar para así poder pasar página y comenzar desde cero; como si nada hubiera pasado y nadie hubiera sufrido. No obstante, muchos de estos presos y presas, una vez en libertad, sintieron la necesidad de inmiscuirse en la difícil labor de re-crear los episodios más aberrantes de su historia personal y con ello permitieron el maridaje de dos disciplinas: la historia y la literatura. En este ensayo vamos a analizar cómo estas experiencias personales se convierten en material literario atendiendo al género literario desde el que se narran, a la disyuntiva entre ficción y no ficción y al valor estético, retórico y temático de los textos que recogen dichas vivencias. Las obras a estudiar son: En el infierno. Ser mujer en las cárceles de España (1977), escrita por Lidia Falcón, Desde la noche y la niebla (1978), de Juana Doña, y Las cárceles de Soledad Real (1982), de Consuelo García. Las tres pertenecen al grupo de los primeros 
testimonios publicados sobre las cárceles de mujeres. La relevancia de este estudio radica en la poca atención que la crítica literaria ha puesto en este tipo de obras. Shirley Mangini (1997) en Recuerdos de la resistencia ya presentaba esta realidad con la siguiente afirmación: "no existe una teoría de las memorias individuales o colectivas de la Guerra Civil; esto sucede a pesar de que existe una colección considerable de textos memorialísticos escritos por hombres y mujeres" (Mangini, 1997, p.69) ${ }^{1}$. Este análisis se lleva a cabo bajo el auspicio de una de las premisas fundamentales de la filosofía de Hayden White (2003) que esboza en El texto histórico como artefacto literario y otros escritos. Éste defiende que la literatura y la historia son dos disciplinas que se complementan sin rechazarse: "contar un suceso histórico exige una actividad literaria de creación... que no está reñid[a] con los sucesos que realmente sucedieron" (White, 2003, p. 20). Por eso, estos textos se pueden estudiar no sólo como artefactos históricos sino también literarios. Al escuchar la polifonía de voces femeninas que emana de las prisiones franquistas seremos capaces de conocer a fondo la realidad oculta de estos lugares represivos así como las características de los textos que las describen ${ }^{2}$.

\section{El género literario en los primeros textos sobre la cárcel femenina franquista}

\footnotetext{
${ }^{1}$ El tema de la represión carcelaria franquista sí ha despertado el interés teórico. Dos de los textos más citados son Prisión y muerte en la España de postguerra (1996) de José Manuel Sabín y Libro blanco de las cárceles franquistas (2012) de Ángel Suárez. Existen también algunos estudios dedicados íntegramente a las prisiones de mujeres; véase La revista Studia Historica. Historia Contemporánea en su volumen 29: http://revistas.usal.es/index.php/02132087/issue/view/596. Además, algunos críticos han consagrado parte de su obra al estudio de las cárceles femeninas: Giuliana Di Febo, Fernanda Romeu Alfaro, Mary Nash, Ricard Vinyes y Fernando Hernández Holgado entre otros. No obstante, dichos estudios se centran en la cárcel y sus protagonistas desde un punto de vista histórico y social y no tanto literario. Los ensayos dedicados a las obras que nos ocupan como material literario son escasos. Los títulos más relevantes son: Juana Doña y el manantial de la memoria. Memorias de las cárceles franquistas de mujeres (1978-2007), de F. Hernández Holgado, Writing (in) Prison: The Discourse of Confinement in Lidia Falcón's En el infierno de M. Edurne Portela y Towards a Feminist Reality of Women's Prison Literature: Lidia Falcón's En el Infierno: ser mujer en las cárceles de España, por John P. Gabriele.

2 Aunque hemos elegido estas tres obras como representativas de este periodo temporal, no son las únicas. Para acceder a una recopilación de otros títulos publicados a finales de los 70, los 80 y 90 se puede consultar el ya citado ensayo Juana Doña y el manantial de la memoria. Memorias de las cárceles franquistas de mujeres (1978-2007)
} 
Los textos que versan sobre experiencias carcelarias tienen características propias y definitorias. Lo que en un primer lugar los hace únicos es el lugar de enunciación del que parten, la prisión, que resulta desconocida y enigmática aunque nos pertenece a todos como entes sociales. La crítica que se ha dedicado a establecer el género literario al que pertenecen no consigue converger en un punto común. La taxonomía es variada y se han descrito de diferentes maneras: como pertenecientes a un subgénero de la literatura del trauma (Álvarez, 2007), como novelas con características especiales (Achúgar, 1992), como textos encuadrados en la literatura de resistencia (Nance, 2006), (Beverely, 2004) y/o como textos testimoniales con algo de autobiografía. El interés ante esta disyuntiva nace de una idea de Stanley Fish que recogió y resumió Elzbieta Sklodowska (1996) en Spanish American Testimonial Novel, y es que el lector acomete una lectura predispuesto de antemano por el género que tiene delante. Éste ha aprendido a reaccionar de diferentes formas ante diferentes géneros y esto podría afectar la recepción del lector ante el texto. En este estudio se encuentra dicha disparidad definitoria explicada anteriormente. Estamos ante tres obras que presentan tres géneros diferentes bajo la misma temática y muy parecida intención: el testimonio, el testimonio-novela y el manifiesto. Cada uno de éstos exigirá ciertas estructuras, formalidades y particularidades y, aunque a priori pudieran parecer géneros independientes y desligados entre sí, un análisis en profundidad nos llevará a concluir que comparten muchos de los rasgos principales.

El testimonio es un género que nace en Latinoamérica y en un primer momento definía a textos que tenían que contar con las siguientes características: venir de una fuente directa de conocimiento, tener una documentación fidedigna y poseer cualidad literaria. A estos rasgos se les fueron sumando otras particularidades: carga social e histórica, protagonistas marginales, tradición oral, reacción por parte del lector, etc. Y así como las características se fueron generalizando, el debate en torno al género comenzó a fraguarse. Los mismos intelectuales que habían formado una base teórica sobre el género, comenzaron a atacarlo cuestionando muchas de sus características: la fuente de veracidad implícita, su viabilidad como género o la posibilidad o imposibilidad de surtir efecto social. Estas discusiones están todavía candentes aunque la mayoría concuerdan en la 
hibridez del género y en la característica que John Beverley, crítico por excelencia de este género, estipula como sine qua non de este tipo de textos: el testimonio debe ser representativo de una clase social o de un grupo (Beverley, 2004, p.27). De estos tres textos, sólo el de Soledad Real puede considerarse un testimonio como tal $^{3}$. La protagonista, aunque al principio narra en primera persona, en un punto del texto el pronombre yo se transforma en un nosotras. Esto dice Soledad a su entrevistadora, "¿que por qué digo nosotras cuando te hablo de mí desde el momento en que empieza la guerra? Porque yo todas estas cosas las hago en nombre y como miembro de las Juventudes Socialistas y no las hago sola" (García, 1982, p.53). Beverley estudia el uso del deíctico de primera persona advirtiendo que, mientras que en la autobiografía sirve para construir un ego autónomo, el yo del testimonio no tiene la carga semántica que relaciona el pronombre con una persona específica, sino que es un deíctico que puede ser asumido indistintamente por cualquiera (Beverley, 2004, p.35). El crítico acepta que el testimonio puede mostrar el crecimiento y transformación del narrador pero siempre asociado al de un grupo o clase marcado por la marginalización, la opresión y/o la lucha. En el momento que Soledad Real transmuta el yo por el nosotras, el texto adquiere su valor testimonial.

Desde el punto de vista del género literario, la obra de Juana Doña es algo más compleja pues se erige como novela-testimonio ${ }^{4}$. Beverley afirma que nos situamos ante una novelatestimonio cuando un autor, en el sentido convencional, o ha inventado una historia similar que se podría considerar testimonio, o la ha revisado extensamente con explícitos objetivos literarios tales como densidad figurativa, forma narrativa más concisa, eliminación de disgresiones e interpretaciones, etc. (Beverley, 2004, p.38). En el caso de Desde la noche y la niebla, es evidente

\footnotetext{
${ }^{3}$ Las cárceles de Soledad Real describe la vida de la protagonista desde su infancia hasta su madurez haciendo hincapié en el paso de ésta por diferentes cárceles femeninas. Al leer esta obra aprendemos el papel que la mujer tuvo durante la guerra civil española así como su despertar de conciencia como ente polítco y social.

${ }^{4}$ Desde la noche y la niebla relata la vida de Leonor a partir de febrero de 1939, su detención, su larga estadía en diferentes prisiones femeninas franquistas como presa política y su puesta en libertad. De la mano de la protagonista y sus compañeras de prisión el lector conocerá la realidad de las mujeres que sufrieron la represión dictatorial y cómo éstas consiguieron sobrevivir al aparato punitivo franquista.
} 
que la autora no ha inventado el testimonio sino que ha dotado a su experiencia de calidad literaria. Parte de lo que hace a esta obra un testimonio es el uso de dos pronombres que aluden a un grupo o colectividad: ella -la protagonista que representa a la mujer en general- y nosotras. El uso de ella, que se corresponde a Leonor, la protagonista, nace de la necesidad de clandestinidad que pedía esta obra. Leonor es la propia autora desdibujada por temor a la censura de un franquismo todavía activo en 1967, cuando comienza su labor escrituaria. Así lo explica Doña al justificar la existencia de este personaje con nombre ficticio: "me topaba con la clandestinidad, donde no podía poner nombres auténticos para relatar hechos reales" (Doña, 1978, p.16-17). Los pronombres tienen la función de salvaguardar identidades en un proceso de desdoblamiento. Así, ella es Leonor, que a la vez es Juana Doña, que a la vez representa a la mujer que sufrió la condena franquista. El pronombre nosotras es sin duda el que impera en este testimonio. Representa a la colectividad del conjunto de mujeres castigadas por el fascismo. No obstante, al leer la obra como un todo narrativo, se puede apreciar que la gran protagonista de la misma es Leonor y la mayoría de los acontecimientos dentro de la cárcel giran en torno a lo que le sucede en relación con las demás, por lo que deducimos que todavía existe una intención de mostrar un avatar personal. Sólo en el manifiesto de Falcón el pronombre de primera persona desaparece casi en su totalidad hasta el punto que el lector, al finalizar su lectura, no sabrá mucho de la experiencia personal de la escritora, ni siquiera el porqué de su condena, sino lo que sufrió la mujer en general.

En el infierno, de Lidia Falcón (1977) pretende ser un homenaje a todas las mujeres que han tenido que cumplir la condena de ser mujer en una dictadura de hombres ${ }^{5}$. Al contrario de lo que pasara en los dos testimonios anteriores, Falcón parece disociarse, en lugar de asociarse, con el resto de protagonistas. La propia autora cataloga genéricamente su texto indicando que se trata de un manifiesto. En Falcón se descubre a la escritora comprometida con la causa feminista, hasta el

\footnotetext{
${ }^{5}$ En el infierno: Ser mujer en las cárceles de Franco se escribe como una recopilación de apuntes sobre la experiencia carcelaria de Lidia Falcón y sus compañeras. El estilo es irónico, directo y sagaz y de su lectura se extrae un claro mensaje: poner en tela de juicio el entramado penitenciario franquista que pretende la destrucción del cuerpo de toda mujer que no se adscriba al concepto de feminidad impuesto por el régimen dictatorial.
} 
punto de llamar al texto el " «libro feminista»... El primer Manifiesto Feminista, hoy a punto de terminar. La primera vez que se definía a la mujer como clase" (Falcón, 1977, p. 229, 234). Carlos Mangone y Jorge Warley o Venko Kanev son algunos de los críticos que han estudiado las peculiaridades de los manifiestos llegando a conclusiones diferentes. Mangone y Warley (1994) no dudan en afirmar que el manifiesto pertenece a la literatura de combate, mientras que Kanev (1998) lo categoriza como literatura pragmática. Este último teórico nos presenta las características más sobresalientes de los manifiestos y todas ellas aparecen de manera clara en la obra que nos ocupa: a) "es la máxima expresión de una ideología naciente que aspira a ser dominante cuestionando y negando la anterior" (Kanev, 1998, P.12) b) es "rebelde" y por ello hace uso de ciertas figuras estilísticas que ayudan a crear esta sensación de rebeldía, c) tiene una función emotiva o expresiva y d) tienen valor colectivo, por lo que "el emisor habla en nombre de un grupo, de un conjunto de ideas comunes y se dirige a un público numeroso." (Kanev, 1998, P.12). Puesto que el emisor representa a un grupo y sus ideas, el pronombre que suele imperar es uno de tercera persona, o singular o plural. En este caso, ella -la mujer-, ellas -las mujeres- y -ellos- los detractores. Pero los deícticos ella, nosotras y ellas/os no son los únicos bajo los que se articulan estos textos. Por definición, el testimonio y el manifiesto piden la colaboración de un lector activo, involucrado y atento. Según Kanev, en ambos géneros existe "una búsqueda del efecto inmediato en forma de actuación que rechaza por definición el deleite de la lectura pasiva" (Kanev, 1998, p.15). Por lo tanto este lector/tú se convierte también en parte principal de la obra. Sin embargo, el uso de este pronombre puede resultar problemático. A continuación consideraremos las peculiaridades de este pronombre en estos textos poniendo especial atención en Las cárceles de Soledad Real.

El pronombre tú adquiere una importancia relevante puesto que éste se puede permutar en dos opciones posibles, el tú-lector o un tú-intermediario que recopila y organiza el material oral. El texto de Soledad Real es el único en el que aparece la figura de este compilador, o alocutario para usar un término de Renato Prada Oropeza (2001), quien en El discurso testimonio y otros ensayos hace un estudio contundente del papel del mismo. La existencia del alocutario ha despertado 
algunos debates sobre la cuestión de la autoría y la manipulación del material oral. Antonio Vera León (1992), en "Hacer hablar: La transcripción testimonial," informa que este tipo de obras sufre un filtraje mayor que otras puesto que, desde que el protagonista narra hasta que esta narración ve su publicación, lo narrado ha sido matizado por dos o tres plumas diferentes, siendo la del alocutario una de ellas. En Las cárceles de Soledad Real, dicho alocutario es una periodista que actúa movida por un "deseo de comprender la historia" (García, 1982, p.49). La periodista articula el texto en base a una entrevista y la simple elección de unas determinadas preguntas podría representar ya un indicio manipulativo. No obstante y siendo conscientes de la existencia de una mano que manipula la información primaria, estos escritos importan no tanto por quién los firma sino por la historia que cuentan. El material que tratan es sumamente delicado, pues se ven salpicados de altas dosis de violencia y sufrimiento extremo. Leonor, Soledad, Juana Doña, Consuelo García y Falcón nos reclaman como interlocutores activos y nos abren las puertas de estas cárceles no de manera altruista, sino para que el lector reaccione de alguna manera y es aquí donde radica el utilitarismo propio del género testimonial y del manifiesto.

De este modo, vemos cómo estamos ante géneros híbridos que se entrelazan, se prestan características, se permutan. Mientras que cada uno tiene rasgos definitorios claros, existen aspectos que se repiten en todas las obras. En un primer lugar se percibe la necesidad que las autoras sienten de que lo vivido no desaparezca con ellas. Al recomponer su existencia en la cárcel, o la existencia de otras como ellas, presentan la fidelidad a una misma, a una ideología o a una colectividad. Además, los tres textos están dotados de carga histórica, social y política y dan voz a uno de los grupos más marginados durante la Guerra Civil y el franquismo. Pero la literaturización de estas historias no pasa sólo por inscribirlos en un género. Hay otras peculiaridades que les otorgan valor literario. A continuación se va a analizar cómo estos artefactos se sitúan entre dos esferas, la ficticia y la no-ficticia y la urgencia por ello de mantenerse activos ante el texto. 


\section{El elemento ficcional en los primeros textos sobre la cárcel femenina franquista}

Juana Doña y Lidia Falcón, en algún momento de su existencia, decidieron hacer públicas experiencias que hasta ese momento habían pertenecido a la esfera de lo privado-personal. De igual modo, Consuelo García relató la vida de Soledad Real creando así un personaje público. Pero cuando una persona acomete un proceso de recreación indefectiblemente entran en juego algunos procesos a tener en cuenta: el lapsus de tiempo entre lo vivido y lo escrito, las intenciones últimas del que narra, que provocan una pre-selección del material que interesa presentar, y la labor mnemónica y sus peculiaridades: la fragilidad, el olvido o el desdibujamiento de los hechos. Estos son los procesos que provocan la ficcionalización en estos textos. Ficción no es entendida aquí como sinónimo de invención apartada radicalmente del dato histórico, sino como elemento que, basándose en hechos factuales, pasa por un proceso de reinvención. Bettina Pacheco, en Mujer y autobiografía en la España contemporánea (2001), explica dicho proceso a través del concepto de la mentira autobiográfica: "escribir una vida, es lo mismo que revivirla; es decir, reescribirla y reinventarla: he aquí la ficción" (Pacheco, 2001, p.30). Hayden White también se hace eco de este proceso de ficcionalización arguyendo que no toda ficción es historia, pero todas las historias son interpretaciones ficcionalizadas de los acontecimientos que describen (White, 2014, p.82). Resulta esclarecedor que este tipo de obras comience con uno o varios paratextos donde el autor, editor o prologuista advierte o no del ingrediente ficcional. Gérard Genette (1989) identifica los siguientes tipos de paratexto: "título, subtítulo, prefacios, epílogos, advertencias, prólogos... epígrafes, etc." (Genette, 1989, p.11-12). En la parte introductoria de Desde la noche y la niebla Juana Doña afirma que todo lo narrado es real, sin haber inventado nada: "quiero dejar constancia, que ni uno solo de los relatos que se cuentan aquí, son producto de mi imaginación" (Doña, 1978, p.17) y otorga a Alfonso Sastre la labor de prologuista. Éste advierte que el lector va a encontrar elementos que difieren algo de la realidad: "lo imaginario se reduce" o "[existen] algunos retoques" (Doña, 1978, p.12). Por su parte, Lidia Falcón niega cualquier elemento ficticio y acusa de necio a todo lector que le tache de mentirosa: "quede advertido el lector, que todos los personajes que describo existen... sin 
que mi imaginación haya desfigurado un suceso... Quienes así lo crean... son los que no ven, los que no quieren saber" (Falcón, 1977, p.22). De este modo se aprecia cómo las autoras sienten la necesidad de advertir de una veracidad que quedará en entredicho; o bien a través de las advertencias de un prologuista, o bien a través de una lectura consciente por la que se concluye que la ficción- o reinvención- también es parte de estos textos, y que en ella, como señalara Hayden White, se encuentran las disciplinas de la historiografía y la literatura. A la absoluta apelada veracidad -u objetividad- se le enfrentan aspectos citados anteriormente: el papel de la memoria y el lapsus de tiempo.

La vuelta al pasado a través de la rememoración se convierte en condición axiomática en los textos que nos ocupan. Roberta Culbertson, en su ensayo Embodied Memory, Transcendence, and Telling: Recounting Trauma, Re-establishing the Self (1995), estudia cómo la persona que ha sido víctima de brutalidades draconianas procesa, guarda y exterioriza lo que su cuerpo y mente almacenan en forma de recuerdos. La violencia surte un doble efecto en los que la sufren: una necesidad de silenciar todo lo ocurrido y una sensación de que los recuerdos almacenados en la mente persiguen a la víctima. Este silencio es interno y externo: la víctima no cuenta lo que recuerda... en parte por la convicción que nadie la creerá pero basicamente porque no puede transformar los recuerdos en palabras (Culbertson, 1995, p.169). Sin embargo, este silencio impuesto y a priori necesario, es superado en todos estos testimonios, siendo ésta una de sus características primordiales. Las autoras de este tipo de textos a menudo reflexionan sobre el momento en el que deciden dejar fluir sus experiencias pasadas aceptando haber guardado todos los recuerdos y afirmando que el paso del tiempo no ha conseguido alterar su percepción de lo acontecido. Así lo narra Doña: "Cuando en el 67 escribí este relato, aún mantenía muy vivo el recuerdo de mis años de prisión, el de las mujeres que vi sacar a fusilar, de aquellas otras que murieron a mi lado, de las que sobrevivimos..." (Doña, 1978, p.16). Culberston explica que la reinserción social pasa por este proceso de auto-narración. Doña habla de esta urgencia narrativa, aunque parece que su intención es por el bien común de la mujer como grupo social: "cuando 
escribí este relato ya me urgía que se conociera todo el horror de veinte años en las cárceles franquistas de mujeres" (Doña, 1978, p.15). No obstante, una lectura crítica y atenta permite que el lector descubra algunos indicios que ponen de manifiesto algunas interferencias de la memoria en el acto narratológico; por ejemplo, la precisión con la que Doña recuerda fechas, números y diálogos entre carcelarias. Diez años pasan entre la puesta en libertad de la autora, 1957, y el final de la redacción del texto. Resulta poco probable que los datos otorgados por Doña sean un fiel reflejo de la realidad. El testimonio de Falcón, aunque se escribe mientras ella está en la cárcel, por lo que no hay tal proceso de fosilización de los recuerdos, también presenta ciertos problemas puesto que a veces relata historias que le han sido contadas a la autora y que ella no ha vivido en primera persona. De este modo, y aceptando la fragilidad de la memoria como un hecho, se entiende que estos escritos no pueden ser reflejo perfecto e íntegramente fiel del pasado. No obstante, adquieren un importante valor como elemento sustentador del movimiento de la Memoria Histórica en España, un intento de recuperar la memoria de los vencidos y sus familiares que comenzó en el siglo XXI. Estas obras, por lo tanto, se erigen como lugares donde esta memoria perdura y asisten en la labor revisionista de la otra-historia, yuxtaponiendo la memoria no oficial de los vencidos a la memoria franquista, la que se había presentado como oficial y única. Otro elemento a considerar en el estudio del proceso de literaturización es cómo el dato personal se embellece y se reviste con tropos y ornatos que le otorgan una belleza que posibilita que los aberrantes atropellos hacia la mujer adquieran valor retórico y estético.

\section{El embellecimiento de los primeros textos sobre la cárcel femenina franquista}

En estas obras se percibe una evolución que va desde la aparente ausencia de figuras estilísticas en Las cárceles de Soledad Real a un uso consciente de tales figuras por parte de Doña y Falcón. Pacheco afirma que "lo que fue vida pura y simple precisará de cierto maquillaje para lograr su valor estético, así como un sentido valor humano" (Pacheco, 2001, p.30). El testimonio de Soledad Real fue escrito por una periodista que se adhiere a la fidelidad al discurso. Al hacer esto se cumple lo 
que Kimberly Nance determina en The Capacities and Constraints of Testimonio's Speakers and Experiencing Writers cuando afirma que los textos que transcriben directamente la oralidad del testigo pecan de repetitivos, monótonos y excesivamente verbales hasta el punto de desgastar la lengua (Nance, 2006, p.110). García, en un intento de respetar al máximo la figura de la protagonista transcribe directamente la conversación entre ambas. El texto se construye a partir de un esquema pregunta-respuesta y este mecanismo nos pone en contacto directo con la técnica principal del texto, la oralidad y dos de sus características principales: la falta de estructura en el relato y un uso vulgar del lenguaje debido al analfabetismo de las protagonistas. El texto contiene abundantes diminutivos, así como vulgarismos y expresiones coloquiales: "y llegar a tu casa y meterle una hostia a tus hijos" (García, 1982, p.37). Además, la oralidad hace posible que el lector se identifique directamente con el protagonista. En su apelación a Consuelo García, Soledad se dirige directamente al lector: "y ten presente una cosa, que también aceptábamos esta inferioridad" (García, 1982, p.36). De esta manera, Soledad establece una conexión directa con el lector que no se encuentra en los otros textos.

Las figuras estilísticas de la novela-testimonio Desde la noche y la niebla tienen un claro cometido: provocar la empatía del lector. Uno de los tropos más recurrente es la intensificación, lograda con la yuxtaposición de sustantivos y adjetivos. Además, el texto cuenta con abundantes personificaciones, metáforas e imágenes sensoriales, que a veces consiguen situarlo más cerca del lenguaje poético que del narrativo: "estrella perezosa" o "corría alocadamente.... Tragándose la oscuridad de la calle" (Doña, 1978, p.23, 34). Las figuras retóricas no crean un mundo fictivo desconectado del tema principal, el paso de Leonor por la cárcel, sino que están al servicio de esta historia para embellecerla y dotarla de calidad literaria. Estas figuras estilísticas que intensifican las vivencias de las protagonistas permiten crear un texto que resalta por su intensidad y emotividad.

La finalidad última del texto de Lidia Falcón es imputar al aparato franquista por la situación de la mujer española de los setenta en general y de la condenada en particular. La ironía, el humor en forma de risa carnavalesca y la pregunta retórica son las figuras predominantes. Linda Hutcheon 
(1992) establece en Ironía, Sátira, Parodia. Una aproximación pragmática a la ironía, que este tropo tiene como una de sus características principales un señalamiento evaluativo que se vuelve casi siempre peyorativo. Esta evaluación que se hace de la realidad funciona a dos niveles, el semántico y el pragmático, y sólo entendiendo ambos se puede llegar a comprender el recurso irónico en su totalidad. En los testimonios previos las figuras literarias existentes eran simples de desmembrar y apenas alteraban la comprensión del texto. En la obra de Falcón, la labor del lector es más compleja ya que tiene que ser capaz de descodificar el mensaje: "la ironía es, a la vez, estructura antifrástica y estrategia evaluativa, lo cual implica una actitud del autor-codificador con respecto al texto en sí mismo. Actitud que permite y exige, al lector-descodificador, interpretar y evaluar el texto que está leyendo" (Hutcheon, 1992, p.177). Falcón parece anunciar la importancia de la ironía en su texto cuando nada más llegar a la cárcel las presas equivocan este lugar con un paraíso:

Cuando el furgón se detiene...la prisión abre sus puertas para enseñar a la reciente inquilina las paredes blancas, las camas de sábanas limpias y las duchas de agua caliente, un nuevo paraíso parece haberle acogido. Todas las delicadezas del hábitat femenino están reservadas para ella (Falcon, 1977, p.36).

De este modo la ironía se convierte en un juego de equívocos que nos muestra la intención del autor a partir de expresar lo contrario de lo que piensa. Junto con este tropo hay que destacar el uso de otras dos figuras retóricas: la risa carnavalesca y las preguntas retóricas.

La risa carnavalesca implica una actitud contestataria hacia una persona o, en este caso, un sistema de gobierno. A través de este tropo se intenta desestabilizar el sistema a la vez que el escritor permite una descarga de tensión en la obra. Roberto Echevarría Marín (2006) hace un estudio del significado del concepto de risa carnavalesca, acuñado por Mikhail Bakhtin, afirmando que "esboza un espacio contestatario, dimensión dialéctica en la que desaparecen las inequidades sociales y se impugna la moralidad política e ideológica de las instancias de poder" (Echevarría, 2006, p.55). Falcón introduce una escena que nos pone en contacto con este tipo de humor sugerente. En el capítulo XIII, "No me toques, soy impura," se presentan enfermedades y epidemias 
latentes en los complejos penitenciarios. Así se narra un brote de ladillas que afectó a las carcelarias:

todas las presas iban rascándose descaradamente por los patios y los pasillos, como si quisiesen hacer alarde de la enfermedad, o provocar el asco y la repulsión de las funcionarias... el director veía como crecía cada día el número de las que se rascaba el sexo, con una cierta sonrisa maligna, sobre todo cuando le tropezaban en algún patio, haciendo los más obscenos movimientos que les permitía la ropa (Falcón, 1977, p.19899).

La actitud contestataria de las presas se muestra en los tocamientos obscenos en presencia del directo. Dichos tocamientos ponían de manifiesto comportamientos que iban en contra del imaginario feminista franquista según el cual una mujer debía ser decorosa, púdica y recatada.

El recurso de la pregunta retórica intercepta al lector invitándole a una reflexión más detallada de la situación penitenciaria: “¿es posible condenar sin escuchar, juzgar sin pruebas, sentenciar los sentimientos, las ideas, las intuiciones?" (Falcón, 1977, p.65). Como afirma Ángel Romera en el Manual de retórica, (n.d.) este tipo de preguntas que no esperan respuestas representan en su estado más puro una forma de aseveración suave. De este modo, entre la ironía, la risa carnavalesca y la interrogación retórica, se establece un contrapunteo que conforma una crítica desestabilizadora del franquismo. Con el uso de estas figuras, Falcón se desliga de las otras autoras en lo referente al dominio de la lengua y sagacidad en la expresión. John P. Gabriele (1995) reflexiona de esta manera sobre el estilo de Falcón: "si su relato... conmueve a los lectores, no es principalmente debido a los sucesos en sí, sino a la maestría por parte de Falcón en el arte de la retórica y en el de la ficción" (Gabriele, 1995, pp.95-96). Las tres obras tienen como meta principal enjuiciar un sistema político y dar a conocer a las que lo sufrieron; sin embargo, sólo Falcón es capaz de subvertir el propio lenguaje usado por este sistema para presentar sus defectos. Una vez analizado el proceso de embellecimiento vamos a centrarnos en el valor de estos textos desde un punto de vista temático. Se estudiarán los temas más recurrentes pero atendiendo a una evolución 
que se establece al enfocarnos en el momento en el que cada protagonista cumple condena. Con ello se entenderá cómo las prácticas carcelarias franquistas fueron cambiando a la par que lo hacía el propio sistema.

\section{La temática de los primeros textos sobre la cárcel femenina franquista}

Los análisis sobre los testimonios de presidiarias durante la dictadura española se centran principalmente en la temática de los mismos. La mayoría coincide en señalar el dolor, la violencia, la rebelión y la solidaridad como los temas principales. Si bien esto es del todo cierto, ningún estudio se ha centrado en presentar la evolución temática de los mismos. Por ello, en este apartado se analizará dicha evolución como manera de entender la cárcel como uno de los lugares del siglo veinte, según la definió Ioan Davies (1990) en Writers in Prison. Al emprender este análisis se podrán observar dos realidades en cuanto al contenido temático: una que habla de temas iterativos y otra de temas que surgen dependiendo del momento socio-político en el que las protagonistas cumplen condena.

Ioan Davies determina que la escritura sobre la cárcel trata principalmente del tema de la violencia... Es una contemplación de la muerte, nuestra muerte, la muerte que imponemos en otros, la muerte impuesta en nosotros por otros. (Davies, 1990, p.16). Efectivamente, los tres testimonios coinciden en mostrarnos una historia de violencia, suicidios y muerte. Las cárceles del franquismo se constituyeron como jaulas donde cualquier tipo de abuso estaba permitido. Desafortunadamente, no podemos hablar de evolución en la práctica de vejaciones pues el testimonio de Falcón, presa en los albores de la Transición, presenta duras escenas de atropellos contra la mujer. Soledad y Juana Doña cumplen condena durante los primeros años de la dictadura. Soledad lo hará de 1941 a 1957 y Juana Doña de 1939 a 1941 y de 1947 a 1961 . Mientras que en los testimonios de éstas la violencia que se describe es despiadada y ocupa gran parte del contendio de la obra, en el de Falcón, encarcelada en diferentes momentos de 1972, 1974 y 1975, no existen palizas corporales sino violaciones sexuales. Existen dos razones que explican esto. La primera es 
que en los setenta, el franquismo había sufrido diferentes mutaciones y su objetivo primordial no era ya aniquilar al enemigo político. Las presas de los primeros testimonios son políticas, las de Falcón, en su mayoría, sociales. La otra razón es que Falcón intenta hacer de su texto un manifiesto feminista y por ello necesita detenerse en las infracciones contra el sexo que biológicamente distingue a la mujer. Es relevante observar la evolución en cuanto a este tema. Mientras los primeros testimonios reparan más en el cuadro descriptivo de las acciones, dando detalles a veces sumamente escabrosos, el de Falcón no presenta tanto el acto de la violación como las consecuencias que se derivan de la misma: el devenir físico y la deformación. Los atributos sexuales de la mujer: el pelo, el pecho y la cintura se deforman permitiendo que la mujer pierda su feminidad definitoria:

[...] meses después del ingreso, una mujer que entró bien arreglada... ha aprendido a comer con las manos, ha visto crecer su pelo teñido periódicamente convirtiéndose en una masa de estopa de varios colores, con una raya gris o negra que avanza inexorablemente en la conquista de toda la cabellera (Falcón, 1977, p.104).

Hablar de evolución temática exige abordar uno de los temas por excelencia de estos textos: la resistencia y los diferentes matices que esta palabra adquiere. En las obras de Soledad Real y Juana Doña la resistencia se ejerce en diferentes formas: resistir es salvar y burlar la vigilancia de las funcionarias. Resistir es también ser portadora de un nuevo espíritu que se activa después de haber sido víctima de tanta violencia: "el espíritu invencible de los vencidos" (Doña, 1978, p.127), que hace reaccionar a los presos cuando están a punto de desfallecer. Y resistir es además dedicarse al trabajo por entero como manera de ocupar el cuerpo física y psicológicamente. Esto es lo que dice Soledad sobre el trabajo en la cárcel: "el verdadero recurso era siempre el trabajo. Se proponía, por ejemplo, hacer una obra de teatro. Se hacían ensayos, se hacían los escenarios, los trajes, y así se ayudaba a conservar el nivel moral" (García, 1982, p.132). Sin embargo, en el manifiesto de Falcón ocurre algo diferente. El espíritu positivo e invencible de las carcelarias políticas franquistas desaparece y con ello cualquier conato de resistencia. De hecho, mientras que Soledad y Leonor 
rematan sus textos con su puesta en libertad, muchas de las protagonistas de Falcón terminan encontrándose otra vez en la cárcel tras haber gozado de cortos periodos de libertad. No en vano el último capítulo se llama El ciclo se ha cerrado. Es el ciclo vital de mujeres que vuelven a la cárcel por reincidentes. De este modo, la resistencia que se nos plantea en los primeros testimonios como uno de los ejes temáticos se vuelve en En el infierno algo difícil de lograr. A la autora no le interesa mostrar el deseo de superación de sus protagonistas sino la inmundicia del ambiente carcelario propiciatoria de la involución personal de las presas sociales de los últimos años de la dictadura.

Lidia Falcón presenta una evolución temática debido a las condiciones sociales de la década de los setenta. El primer aspecto que sobresale es la despersonalización y ausencia de identidad ideológica. Las protagonistas de En el infierno representan para el franquismo el peligro de ser individuos que, por una u otra razón, no interesan como componentes activos de la sociedad. La cárcel se convierte así en el hábitat de los desechos sociales: prostitutas, homosexuales, oligofrénicos, etc. De entre ellos sobresale la presencia de prostitutas. Se las describe así: “pobres, todas eran pobres... De las treinta mil rameras de Madrid, ochenta encarceladas. Siempre las mismas... putas de callejón, de camastro alquilado, de figón de puerto" (Falcón, 1977, p.134) ${ }^{6}$. La autora critica que la prostitución nace en el propio seno franquista, en las mismas cárceles a donde reincidentemente vuelven estas mujeres a las que no se les ofrece ninguna posibilidad evolutiva. Aunque en el testimonio de Falcón el argumento de la prostitución se torna como uno de los principales, no presenta ninguna novedad temática. En los testimonios de Soledad y Leonor encontramos condenas por la misma causa. La novedad radica en la forma en que estas mujeres son entendidas y tratadas. Mientras Falcón siente una total aceptación ante este grupo, Soledad y

\footnotetext{
${ }^{6}$ Jean-Louis Guereña (2003) estudió el tema de la prostitución en España durante la Guerra Civil y dictadura llegando a las siguientes conclusiones: la prostitución fue una práctica aceptada por los dos bandos durante la Guerra Civil. Tras la guerra, la policía franquista se ocupó del caso de la prostitución llevando a cabo una vigilancia de las casas de citas pero permitiendo legalmente el concurso de esta actividad. En 1941 surge el Patronato de Protección a la Mujer con la misión de encauzar la vida de las prostitutas. Aun así, "nadie cree que pueda aconsejarse la supresión radical de la prostitución reglamentada" (Guereña, 2003, p.424). En 1956 se promulga el decreto abolicionista de esta actividad por lo que muchas prostitutas terminaron en el subsuelo penitenciario franquista.
} 
Leonor muestran ciertas reticencias ante sus compañeras prostitutas. No sólo la prostituta es carne susceptible de prisión; la homosexual también comparte celda y castigo con la primera por no adaptarse al concepto de feminidad impuesto socialmente durante la dictadura.

La homosexualidad fue duramente perseguida durante el franquismo. En el infierno se aprecia como esta condición era para el Régimen una de las peores faltas en la mujer. Así un juez grita a Concepción, la lesbiana del relato, “imejor te hubiera valido ser puta!" (Falcón, 1977, p.153). La autora plantea en su obra una dura crítica hacia la recalcitrante conciencia machista que niega la posibilidad que las mujeres puedan tener una relación homosexual: “¿quién podría admitir que una mujer apreciara la tersura de la piel, la sensualidad de los senos y de las nalgas femeninas?" (Falcón, 1977, p.153). Aunque no se expresa explícitamente en el texto, se sugiere que la homosexualidad representaba una posible amenaza para el género masculino, ya que estas mujeres no se avenían al delimitado molde femenino creado durante el franquismo. Lucía Guerra (2007) en Mujer y escritura. Fundamentos teóricos de la crítica feminista observa que la homosexualidad femenina pone en entredicho la hegemonía del falo y el concepto de unidad que pende de las relaciones heterosexuales. La mujer se muestra independiente, activa y agente de su propia penetración. Como pasara con la prostitución, Leonor y Soledad también reflexionan sobre este tema aunque de forma prejuiciosa. Resulta interesante observar cómo en la década de los cuarenta, incluso las comunistas, consideradas ideológica y socialmente las más avanzadas, rechazaban la libertad sexual. Soledad culpa a "los prejuicios propios de [su] educación y de aquel tiempo" (García, 1982, p.146). Junto a la prostitución y homosexualidad se presenta otro grupo de personas que completan este abanico de inadaptados sociales, los retrasados mentales, que no aparecen en ninguno de los testimonios analizados con anterioridad.

De este modo podemos concluir que la temática evoluciona en base a dos coordenadas. Por una parte hay temas que se repiten en cada uno de estos textos: la presentación de los atropellos hacia el cuerpo y mente de la condenada, la descripción del tipo de presas y las actividades que ocurren en la cárcel o la labor de resistencia como manera de salvación. Por otra parte se entiende 
que hay temas que son particulares del momento socio-político en el que la presa cumple condena. La mayor diferencia radica en lo que significa ser presa política y presa social. En los testimonios de Soledad y Leonor conocemos a las protagonistas y muchas de sus compañeras de manera contundente. Además, hay un gran interés en presentar el despertar político de estas mujeres; despertar que se asocia con la evolución personal y social de las mismas. Por el contrario, en el texto de Falcón, la historia personal de cada mujer desaparece; lo que la autora desarrolla son pequeños fragmentos que le sirven en su propósito de mostrar el colectivo de la mujer y cómo éste está avocado a la involución y ostracismo social que hace de la cárcel uno de los lugares de residencia permanente de muchas de estas presas sociales.

\section{Conclusión}

Este análisis ha demostrado que la literatura y la historia pueden complementarse sin rechazarse. El proceso de literaturización comienza en el preciso momento en el que las autoras sienten la necesidad de narrar experiencias tan personales e íntimas como vejaciones, humillaciones in extremis y constantes y variados atropellos contra la dignidad femenina. Estas narraciones se construyen a partir de géneros como el testimonio o manfiesto, ya que éstos se centran en presentar como personaje principal a un sujeto plural que lucha o defiende una causa común. Además, dichos géneros pretenden mostrarnos una realidad que pide una involucración o reacción por parte del lector. Si siguiéramos el análisis con textos de semejante temática que nacieron a finales de los noventa o principios del siglo XXI veríamos cómo esta tendencia, aunque no desaparece, cambia, pues muchos de éstos fueron escritos por familiares de las víctimas cuya intención era resaltar y encomiar la figura de una persona en concreto.

Durante este ensayo también se ha analizado el valor estético, retórico y temático de estos artefactos, ya que estos valores hacen que el dato histórico/factual sea susceptible de convertirse en literatura. Este proceso de "escribir literatura" pasa por acudir a la memoria y dejarla fluir y a la misma vez que se recuerda, se rememora, se revive y en última instancia se reinventa. La re- 
creación de las experiencias permite que podamos afirmar que junto al dato personal que se convierte en histórico, hay un elemento ficcional. Además, el valor estético y retórico que analizamos se consigue cuando nuestras autoras, especialmente Juana Doña y Lidia Falcón se imbuyen en el proceso escritural. Estas obras, aún presentando las inmundicias del sistema punitivo franquista, están cargadas de expresividad y emotividad. Las escritoras se alían con diferentes tropos y figuras estilísticas para conseguir su cometido final: acercarnos al pasado para denunciar a un sistema, hasta hoy impune, que atacó a la mujer por querer desestabilizarlo. Y es aquí donde reside el valor textual de estas obras.

Las tres nos presentan el panorama de las cárceles franquistas femeninas durante la Guerra Civil y la dictadura. Pero no sólo eso, también descubrimos que pasar por la cárcel, sobre todo la de los primeros años de dicho sistema político, supuso que la mujer adquiriera una consciencia de sí misma que no tenía antes. Esta mujer aprendió a sobrevivir y resistir en una atmosfera que pretendía aniquilarla, y podemos ir un paso más allá, al concluir que al vencer el silencio impuesto, al resistir, al sobrevivir dejaron un legado de incalculable valor. Gracias a ellas y sus textos hoy estamos más cerca de conocer la Historia de los vencidos, los que por muchos años no tuvieron un nombre, una identidad, en definitiva una historia propia.

\section{Referencias:}

Álvarez, J.I. (2007). Memoria y trauma en los testimonios de la represión franquista. Barcelona: Anthropos.

Achúgar, H., John, B. (Editores). (1992). La voz del otro: testimonio, subalternidad y verdad narrativa. Lima-Pittsburgh: Latinoamericana.

Beverley, J. (2004). Testimonio: On the Politics of Truth. Minnesota: Minnesota University Press Culbertson, R. (1995). Embodied Memory, Transcendence, and Telling: Recounting Trauma, Reestablishing the Self. New Literary History 26(1), (pp. 169-95).

Davies, I. (1990). Writers in Prison. Massachusetts: Basil Blackwell. 
Doña, J. (1978). Desde la noche y la niebla. Madrid: Ediciones de la Torre.

Echevarría, R. (2006). La risa carnavalesca. Plaza Crítica 2(2), (pp. 54-60). Recuperado de http://plazacritica.org/articulos06_2/RisaCarnavalesca.pdf

Falcón, L. (1977). En el infierno: ser mujer en las cárceles de España. Madrid: Ediciones de Feminismo.

Gabriele, J. (1995). Towards a Feminist Reality of Women's Prison Literature: Lidia Falcón's En el infierno: ser mujer en las cárceles de España. Monographic Review/ Revista Monográfica 11, (pp. 94-109).

García, C. (1982). Las cárceles de Soledad Real. Madrid: Alfaguara.

Genette, G. (1989). Palimpsestos: La literatura en segundo grado. Madrid: Taurus.

Guereña, J. L. (2003). La prostitución en la España contemporánea. Madrid: Marcial Pons.

Guerra, L. (2007). Mujer y escritura. Fundamentos teóricos de la crítica feminista. Ciudad de México: Universidad Nacional Autónoma de México.

Hernández Holgado, F. (2015). Juana Doña y el manantial de la memoria. Memorias de las cárceles franquistas de mujeres, Arenal 22(2), (pp. 283-309). Recuperado de http://revistaseug.ugr.es/index.php/arenal/article/view/2386/3842

Hutcheon, L. (1992). Ironía, Sátira, Parodia. En, Una aproximación pragmática a la ironía. De la ironía a lo grotesco: en algunos textos literarios hispanoamericanos. Iztapalapa, México: Universidad Autónoma Metropolitana.

Recuperado de https://tallerletras.files.wordpress.com/2013/02/ironc3ada-sc3a1tira-y-parodia.pdf

Kanev, V. (1998). El manifiesto como género. Manifiestos independentistas y vanguardistas, América: Cahiers du CRICCAL 21, (pp. 11-18). Recuperado de http://www.persee.fr/doc/ameri 0982-9237 1998 num 2111357

Mangini, S. (1997). Recuerdos de la resistencia. La voz de las mujeres de la guerra civil española. Barcelona: Península. 
Mangone, C., Warley, J. (1994). El manifiesto. Un género entre el arte y la política. Buenos Aires: Biblos.

Nance, K. (2006). Can Literature Promote Justice? Trauma Narrative and Social Action in Latin American Testimonio. Nashville: Vanderbilt, University Press.

Pacheco, B. (2001). Mujer y autobiografía en la España contemporánea. San Cristóbal, Colombia: Grupo de Investigación en Literatura Latinoamericana y del Caribe.

Portela, E. (2007). The Discourse of Confinement in Lidia Falcón's En el Infierno. Arizona Journal of Hispanic Cultural Studies 11, [121-136].

Prada, R. (2001). El discurso testimonio y otros ensayos. México: UNAM.

Romera, Á. (n.d.). Manual de retórica y recursos estilísticos. Recuperado de <https://www.scribd.com/document/280021870/ROMERA-Angel-Manual-de-Retorica

Sabín, J. M. (1996). Prisión y muerte en la España de postguerra. Madrid: Anaya \& Mario Muchnik.

Sklodowska, E. (1996). Spanish American Testimonial Novel: Some Afterthoughts. En. Gugelberger, G (Ed.), The Real Thing. De Testimonial Discourse and Latin America (pp. 84-100). Durham, North Carolina: Duke University Press.

Suárez, Á. (2012). Libro blanco sobre las cárceles franquistas. Madrid: Planeta.

Vera, A. (1992). Hacer hablar: la transcripción testimonial. Revista de Crítica Literaria Latinoamericana 36, [185-203.

White, H. (2003). El texto histórico como artefacto literario y otros escritos. Barcelona: Paidós. . (2014). The Practical Past. Evanston: Northwestern University Press. 